
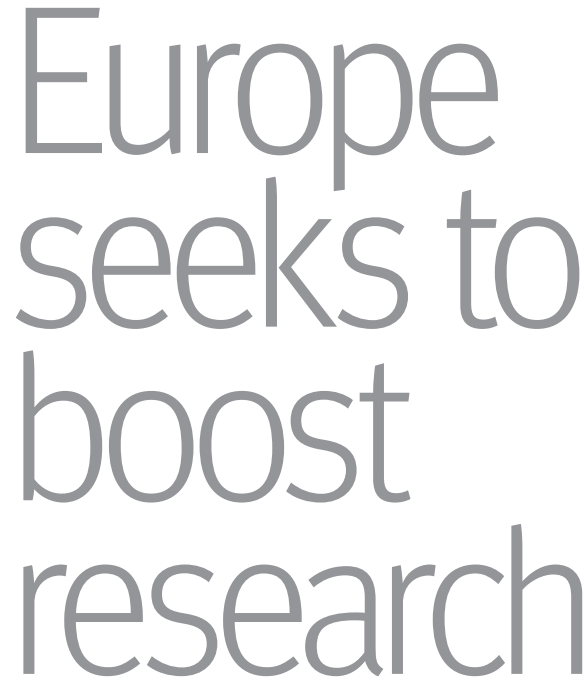

Europe is losing out in the battle for research into potential new treatments. Geoff Watts examines a new initiative to attract more investment

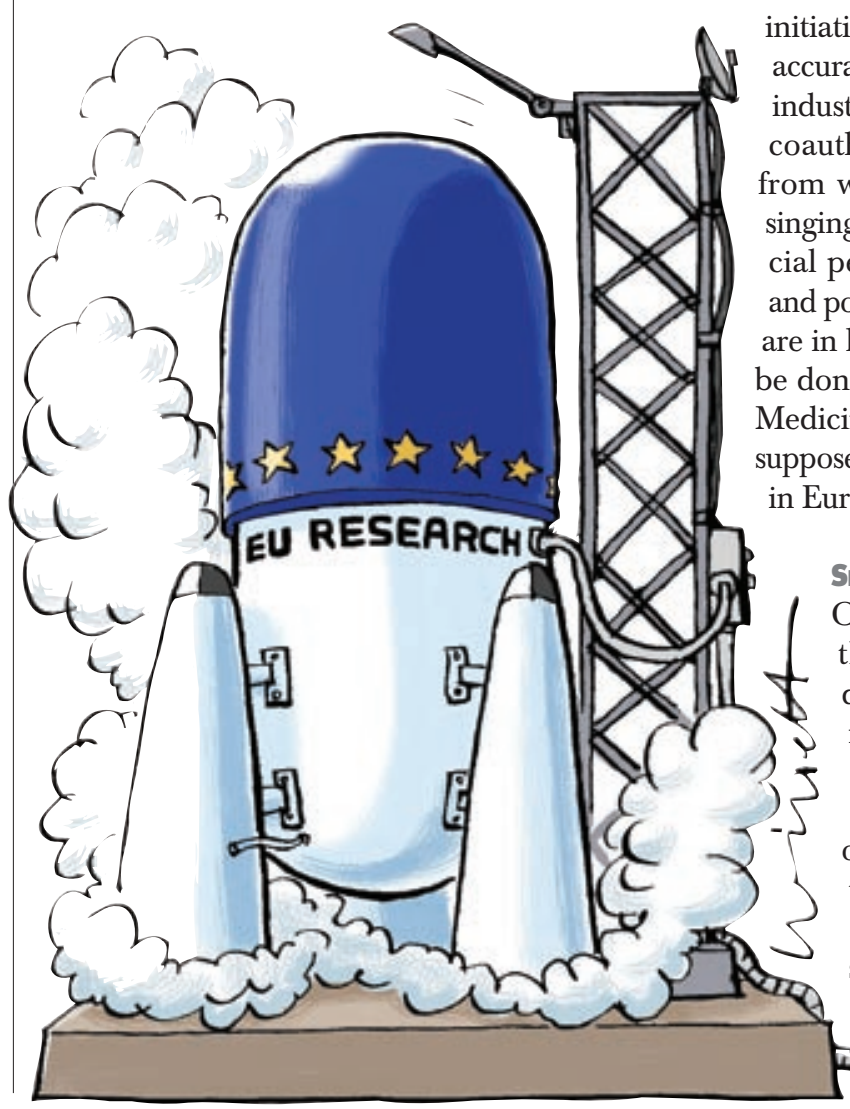

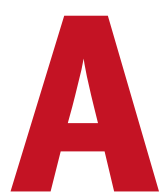

s even the keenest supporters of the European Union might concede, there is not too often reason to use the words "excitement" and "European Commission" in the same sentence. Yet almost all of the people I talked to when researching this article on one of the commission's latest plans used the word "exciting" when discussing its core proposals.

The project generating this unexpected enthusiasm is the Innovative Medicines Initiative, which was given the final go ahead last December. For a succinct summary of what prompted the initiative, look no further than the 2007 edition of The Pharmaceutical Industry in Figures. ${ }^{1}$ Speaking of drug industry investment in Europe it says: "Between 1990 and 2006, R\&D [research and development] investment in the United States grew 5 times while in Europe it only grew 2.9 times . . . The current tendency to close $\mathrm{R} \& \mathrm{D}$ sites in Europe and to open new sites in Asia will show dramatic effects in the next few years if nothing is done to maintain pharmaceutical discovery expertise in the EU."

This is the problem that the new initiative seeks to tackle. Or, more accurately, the problem as the drug industry sees it. The commissioncoauthor of the policy songsheet rom which both groups are now singing-has a slightly less commercial perspective on future threats and possibilities. No matter. The two are in harmony over what needs to done. So what is the Innovative Medicines Initiative? And how is it posed to boost drug development Europe?

\section{Smoothing the research path}

Octavi Quintana, head of the EU's health research directorate, summarises the initiative as a streamlining policy that encourages drug companies to work with each other and with academic institutions, regulators, and patient organisations. "If we're able to streamline the drug development process it will be better for the patients, better for the member countries, and good for the industry and researchers." If the policy succeeds, Europe will be able to create more medicines more speedily, and so make the case for further research investment.

The key to all this is a document published a couple of years ago: the IMI Strategic Research Agenda. ${ }^{2}$ Based on the advice of no fewer than 350 experts working in academia and industry, the document identifies four bottlenecks in drug development (box). The intention is that consortiums of major companies, universities, and patient organisations will bid for the money on offer to tackle specific issues listed in the agenda. And there is cash to back the scheme: $€ 2 \mathrm{bn}(£ 1.5 \mathrm{bn}$; $\$ 3 \mathrm{bn})$ over five years, half from the EU and half from the European Federation of Pharmaceutical Industries and Associations.

Dr Quintana is confident that the four scientific bottlenecks truly are the main squeeze points limiting faster drug development. "We (the commission) did not identify them ourselves," he points out. "We asked the industry and the researchers which were the bottlenecks." And he's equally confident that the scheme as a whole will succeed, not least because everyone has something to gain. "Even member countries that have no drug industry have individual researchers who will be able to contribute."

If all goes to plan the initiative will modernise the development of medicines; attract more investment in biomedical research and development to Europe; anchor jobs in Europe, reversing the current brain drain; and improve the competitive position of smaller companies, thereby enhancing the continent's economy as a whole.

\section{Collaboration and coordination}

This is hardly a modest manifesto. So, while recovering our breath, let's backtrack a step or two. It's true that fewer new chemical entities are being identified and that the cost of developing new drugs is continually increasing. But these are worldwide rather than specifically European problems. So why does Europe need particular help?

The director general of the European Federation of Pharmaceutical Industries and Associations, the companies' trade group, is Brian Ager. Several factors are required to sustain investment in drug research and development, he says. They include a sound system of intellectual property and good 


\section{"We need people to want to be in Heidelberg rather than in Massachusetts or La Jolla or Hyderabad or Shanghai"}

\section{RESEARCH BOTTLENECKS ${ }^{2}$ \\ - Difficulty of making early predictions about the safety of a new drug-Less than $6 \%$ of potential drugs make it from the preclinical stage to market, and one third of failures are because of safety concerns \\ - Difficulty of making early predictions about the efficacy of a potential new drug-Lack of efficacy accounts for a further quarter of the drop out \\ - Inadequate knowledge management-Drug development relies increasingly on information technology to handle large quantities of data about safety and efficacy as well as genetic information \\ - Gaps in education and training in all these areas}

regulatory arrangements. Europe has both. "But a third area where we've always struggled is how to bring together the best brains in academia with the best brains in industrial research laboratories."

The buzz word here is "fragmentation"and not only of European markets and price regulation systems. These certainly pose commercial headaches for the drug industry. But they lie outside the initiative's portfolio, which deals instead with the process and technicalities of early drug development. Think how research proceeds in Europe, says Mr Ager. We've got the universities all right, he adds, reeling off a list ranging from Cambridge to Heidelberg. And we still have a strong industry. What we don't have in Europe is an equivalent of the US National Institutes of Health. This is a powerful driver of research and development in America, funnelling a stream of new findings directly into industry. In Europe we have many countries all going their own way.

The Innovative Medicines Initiative is not, it must be emphasised, seeking to recreate a European equivalent of the National Institutes of Health ("the member states would spend 30 years arguing about where it should be located") but to foster the collaborations between industry and academia that seem to have emerged more naturally in America. "This is very novel," Mr Ager claims. "We've never managed to put together anything like this before in Europe. And that makes it very exciting."

Although the drug industry and the commission are the initiative's loudest cheerleaders, support for it goes far wider. Chris
Watkins, a programme manager at the Medical Research Council, represents the United Kingdom in the international group that acts as a conduit between the planners in Brussels and EU member nations. He echoes what $\mathrm{Mr}$ Ager says about the collaborative element that is such a key feature of the scheme: "What's exciting is the recognition that companies must work together in partnership with universities and patient organisations to address these issues rather than trying to do so individually. Having so many pharmaceutical companies come together in this way is actually quite groundbreaking. I think this could make a substantial impact.”

\section{Emerging competition}

Most of the published documentation about the initiative features comparisons between Europe and America. Asia gets only a passing mention. But speak to any senior executive in the Indian and, more recently, the Chinese drug industry and you soon realise the scale of their ambitions. Having made their mark in manufacturing-first of generics, now of branded products-staff in the smart new corporate headquarters buildings in Delhi and Bangalore are intent on moving into discovery-and in a big way. So to what extent is the prospect of competition with Asia a factor in the creation of the EU initiative?

Dr Quintana denies that intercontinental competition is the key driver. But Mr Ager admits that the drug industry is certainly conscious of the threat. "We keep a track on research facilities that are being opened or closed in Asia as well as in Europe and the US. You see stability in the US with the same number being opened as are closed. You see a greater number being closed than opened in Europe, but in Asia a greater number being opened than closed."

It's only a rough indicator, he admits; but it signals an undeniable trend. If all goes well, the changes pioneered by the initiative should make Europe more attractive. "We need people to want to be in Heidelberg rather than in Massachusetts or La Jolla or Hyderabad or Shanghai."

\section{Will it work?}

The initiative is now issuing its first call for research proposals. Judging its effect when all it has to show are plans is impossible, but at least those plans seem to have earned a thumbs-up from people who should know. When the strategic research agenda was complete, the commission arranged an independent review by a group under the chairmanship of Iain Gillespie, head of the Organisation for Economic Cooperation and Development's biotechnology division. ${ }^{3} \mathrm{He}$ and his fellow reviewers concluded that the initiative is on the right track-though they warn against taking the research agenda as a once and for all plan. It's something to be modified over time and in the light of changing circumstances, says Dr Gillespie.

What is his gut instinct about its likely success? Difficult to judge, he admits. Collaboration among drug companies, although not completely new, is still a relative novelty. But he thinks it could become a trend, particularly where the cost of garnering new information or developing new technologies is cripplingly expensive. All in all he feels that the plan focuses on the right areas, and he doesn't see any major omissions. "It's as good as we're going to get," he says.

The EU's Innomed project is often described as a pilot for the initiative. Innomed is a three year public-private consortium of biopharmaceutical companies and universities that was set up in 2005 to research predictive toxicology and find new biomarkers of drug response in Alzheimer's disease. But as definitive judgments of its value have yet to appear, even this casts only limited light on the initiative's likely outcome.

Any plan put forward by the EU-one of the world's great bureaucracies-can expect critical sniping. But in comparison with the jargon-laced opacities of many of the EU's published plans and documents, those dealing with the Innovative Medicines Initiative are (relatively) easy to grasp. If this clarity of thought can now be realised in decisive action, the dismal downward slide of drug research and development in Europe may yet be halted.

Geoff Watts is a freelance journalist, London geoff@scileg.freeserve.co.uk

Competing interests: None declared.

1 European Federation of Pharmaceutical Industries and Associations. The pharmaceutical industry in fiqures. EFPIA, 2007. http://212.3.246.100/0bjects/2/ Files/infigures2007.pd

2 Innovative Medicines Initiative. Strategic research agenda. 2006. www.imi-europe.org/Publications.as px?viewCategory=Researchx20Agenda.

3 Innovative Medicines Initiative. Assessment of economical and societal effects. 2007. www.imi.europa eu/docs/imi-ia-gillespie-report-032007_en.pdf. 